schizophrenia, exhibiting paranoid delusions and at least three first-rank symptoms, i.e., thought broadcasting, thought echo and auditory hallucinations. He also expressed grandiose delusions, i.e., that he had a special ability to look directly at the sun and that strangers in the street were referring to him as a Chinese leader. He was treated with phenothiazines and discharged after a period of four months, but was re-admitted four days later in a mute, catatonic state. He responded to medication again and was discharged six months later.

He then went to live with an aunt in Hong Kong so that he could work there and earn his fare to China (ostensibly to pursue his idea of becoming a leader). Whilst there, he discontinued his maintenance medication. He then had a strange experience in which he saw a blinding light and knew he was going to be a Chinese leader. Soon afterwards he overheard a conversation between his aunt and her lady friend. The friend was telling his aunt, "I will cut his penis into two". This led to an argument between the patient and his aunt and in the course of the argument the friend shouted and screamed at him saying, "shrink penis, shrink penis". He then left his aunt and went to a neighbour's house for the night. That night he thought his penis was shrinking and experienced acute anxiety and fear. He tried to keep his penis erect by massaging it continuously for the most part of the night fearing that it would disappear into his body, with fatal consequences. He was taken to a nearby hospital in a state of panic still clutching his penis. He was given an injection (? tranquilliser) and discharged the following day. Soon afterwards he returned to England and a few months later (May 1983) was admitted to this hospital in a state of acute panic and recurrence of paranoid symptoms. He said, "My family let my penis go inside", and that his mother and sisters had shouted at him so that his penis would shrink and disappear into his abdomen, killing him. He also subsequently developed a belief that his penis would shrink if he ate noodles. Apart from these symptoms he also complained of palpitations, feeling hot and excessive sweating in the palms and axillae. He responded well to neuroleptic medication in that his schizophrenic symptoms are relatively well controlled but his Koro symptoms are still intact.
This case raises some interesting issues about the nosological status as well as the treatment of Koro states. The symptoms of Koro, even when present in the setting of a primary psychiatric condition like schizophrenia, seem to have a peculiar immunity to conventional neuroleptic medication, suggesting, perhaps, that Koro is an encapsulated delusional disorder similar to paranoia and paranoid states. The conviction continues to be reinforced by the existence of a folk belief, at least in the Chinese. I would be interested to hear about the results of treatment of the full-blown Koro syndrome from your readers.

The Central Hospital,

Madhu H. Padi

Hatton,

Warwick CU34 7EE

\section{THE REAL MENSTRUAL CYCLE}

DEAR SIR,

I must comment on the review by Dr Katharina Dalton of my book, The Real Menstrual Cycle (Journal, 1984, 145, 102).

Dr Dalton asserts that the book is "a far cry" from hormones, prostaglandins and so on. In fact, neuroendocrine processes are of central concern throughout the text and are the subject of a substantial part of the research cited.

There are over 400 references to the reputable international scientific literature. Such a body of work can hardly be said, in Dr Dalton's words, to place too much reliance on "hearsay evidence" or to be unacceptable because it does not use personal examination of menstrual loss or vaginal inspection.

The book does not set out to review the basic physiology or endocrinology of menstruation. It attempts to relate the neuroendocrine processes, as well as learned mechanisms, to the ways in which the physical, psychological and behavioural manifestations of the cycle are experienced. Hence the title of the book.

University of London,

DOREen Asso

New Cross,

London FE14 6NW 